\title{
Structural and optical properties of vacuum-deposited ZnS nanostructures
}

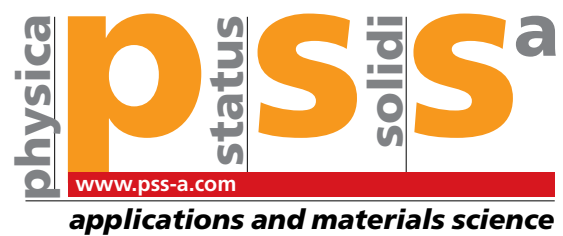

\author{
D. Kurbatov ${ }^{*, 1}$, A. Opanasyuk', D. Sofronov ${ }^{2}$, and H. Khlyap ${ }^{3}$ \\ ${ }^{1}$ Sumy State University, Rimsky-Korsakov Str. 2, 40007 Sumy, Ukraine \\ ${ }^{2}$ SSI "Institute for Single Crystals", NAS of Ukraine, Lenina ave. 60, 61001 Kharkiv, Ukraine \\ ${ }^{3}$ TU Kaiserslautern, Gottlieb-Daimler-Strasse, 67657 Kaiserslautern, Germany
}

Received 24 July 2012, revised 2 October 2012, accepted 5 October 2012

Published online 30 October 2012

Keywords chemical composition, nanostructures, nanowires, optical properties, II-VI semiconductors, structure, ZnS

*Corresponding author: e-mail kurd@ukr.net, Phone: +380 542 334108, Fax: +380 542334049 ,

Web: www.personal.sumdu.edu.ua/kurbatov/eng/, www.sumdu.edu.ua/int/

In this paper some structural, substructural and optical properties of zinc sulfide nanostructures obtained by a CSVS method on bulk ZnSe are investigated. Examination of optical and substructural properties was performed by infrared spectroscopy and X-ray diffraction, respectively. The results of these studies enabled determination of the dependence of the main structural film parameters (texture, lattice parameters, grain and X-ray scattering domain sizes, and microstrain) on the growth conditions. IR-spectral distributions of transmission coefficient $T(v)$ for bilayered $\mathrm{ZnS} / \mathrm{ZnSe}$ nanostructures are obtained.

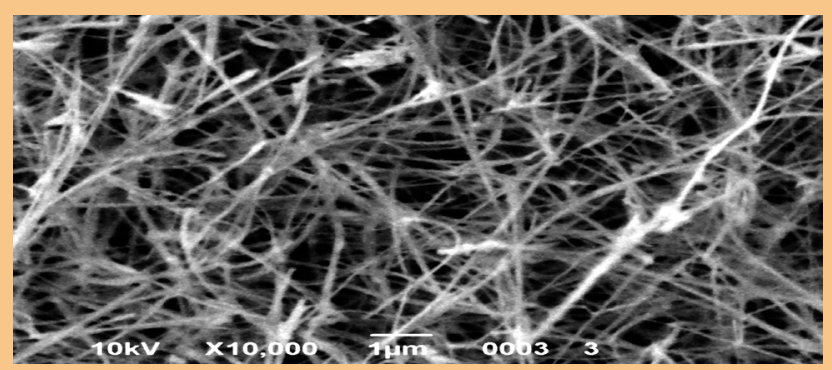

SEM image of ZnS nanowires obtained on (220) ZnSe substrate.
1 Introduction Zinc sulfide as a traditional luminescent material that has attracted attention of material scientists due to its properties that make it suitable for designing new low-cost and reliable solar and photovoltaic devices and opto- (acousto-) electronic active elements. Light-emitting diodes (LEDs), photodetectors, sensors, electro-optical modulators, optical cover layers, etc. based on $\mathrm{ZnS}$ have successfully functioned for decades [1,2]. Zinc sulfide doped with $\mathrm{Cu}$ or $\mathrm{Mn}$ is a good powder phosphor having about $100 \%$ quantum efficiency [3].

ZnS films and nanosized particles are now of particular interest as a perspective base for constructing functional devices with unique characteristics. Among them are nanoscaled electronic devices, lasers, sensors, chemical, gas and biological detectors, and so on [4].

Nanodots, nanorods nanobelts, and films based on $\mathrm{ZnS}$ had been prepared by various methods: vapor-liquid-solid (VLS) process [5], RF sputtering [6], CVD [7], CBD method $[8,9]$, and thermal evaporation $[10,11]$. Commonly, silicon wafers with deposited $\mathrm{Au}$ (or other metal) nanodots were used as the substrates.

Despite the enormous number of references concerning the preparation of $\mathrm{ZnS}$-based nanostructures the question of producing these structures at low substrate temperatures $\left(<500^{\circ} \mathrm{C}\right)$ without a catalyst was not highlighted until recently.

The aim of our work is to show the effect of deposition temperature, on preparing $\mathrm{ZnS}$ films on monocrystalline wafers with large lattice parameter discrepancy, on morphology, structure and substructural features of the layers.

2 Experimental details Films and nanostructures of zinc sulfide were prepared by vacuum evaporation of the material with semiconductor-quality purity in a quasiclosed volume (close-spaced vacuum sublimation (CSVS)) [12]. High-purity monocrystalline cubic ZnSe wafers were used as substrates. The deposition was performed onto the crystallographic (220) plane. The evaporator temperature 
axis of the nanostructure in the lattice of the given phase is determined by taking into account the half-width of the diffraction lines $(L(002)=102.7-113.1 \mathrm{~nm})$ and in the normal direction $(L(110)=16.0-18.5 \mathrm{~nm})$. Comparing these results and data of microelectronic microscopy enabled us to demonstrate that the nanorods are monocrystalline by thickness, at the same time they contain some SCD by length. EDAX and IR spectrometry show the chemical purity of $\mathrm{ZnS}$ films and nanostructures.

Acknowledgements This work is supported by the Ukraine State Agency for the Science, Innovation, and Informatization and by the NRF grant funded by the MEST of Korea (2011-0019204) and by the Ministry of Education and Science, Youth and Sport of Ukraine.

\section{References}

[1] N. K. Morozova and V. A. Kuznetsov, Zinc Sulfide: Preparation and Optical Properties (Nauka, Moscow, 1987), p. 200 (in Russian).

[2] H. Hu and W. Zhang, Opt. Mater. 28, 536 (2006).

[3] T. Kryshtab, V. S. Khomchenko, and J. A. Andraca-Adame, J. Cryst. Growth 275, e1163 (2005).

[4] F. Xiaosheng, Z. Tianyou, and K. G. Ujjal, Prog. Mater. Sci. 56, 175 (2011).

[5] Y. Ding, X. D. Wang, and Z. L. Wang, Chem. Phys. Lett. 398, 32 (2004).

[6] S. Higuchi, M. Ushio, Y. Nakanishi, and K. Takahashi, Appl. Surf. Sci. 33, 667 (1988).

[7] A. Mikami, K. Terada, K. Okibayashi, K. Tanaka, M. Yoshida, and S. Nakajima, J. Cryst. Growth 110, 381 (1991).

[8] B. S. Rema Devi, R. Raveendran, and A. V. Vaidyan, Pramana - J. Phys. 68, 679 (2007).
[9] M. Salavati-Niasari, M. R. Loghman-Estarki, and F. Davar, J. Alloys Compd. 475, 782 (2009).

[10] H. J. Yuan, X. Q. Yan, Z. X. Zhang, D. F. Liu, Z. P. Zhou, L. Cao, J. X. Wang, Y. Gao, L. Song, L. F. Liu, X. W. Zhao, X. Y. Dou, W. Y. Zhou, and S. S. Xie, J. Cryst. Growth 271, 403 (2004).

[11] R. P. Vijayalakshmi, G. Murali, D. A. Reddy, R. Venugopal, and B. K. Reddy, J. Nano-Electron. Phys. 3, 5 (2011).

[12] D. I. Kurbatov, A. S. Opanasyuk, S. M. Duvanov, A. G. Balog, and H. Khlyap, Solid State Sci. 13, 1068 (2011).

[13] Selected powder diffraction data for education and training (search manual and data cards), USA: published by the International Centre for Diffraction Data, 1988, p. 432.

[14] D. K. Bowen and T. K. Brian, X-Ray Metrology in Semiconductor Manufacturing (Taylor \& Francis Group, Oxford, 2006), p. 296.

[15] D. Kurbatov, A. Opanasyuk, and H. Khlyap, Phys. Status Solidi A 206, 1549 (2009).

[16] K. H. Hellwege and O. Madelung, Semiconductor Physics of Group IV Elements and III-V Compounds (Springer, Berlin, 1982), p. 17.

[17] M. M. Ivashchenko, N. M. Opanasyuk, S. M. Danilchenko, and V. V. Starikov, Semicond. Phys., Quantum Electron. Optoelectron. 14, 157 (2011).

[18] A. L. Smith, Applied Infrared Spectroscopy: Fundamentals, Techniques and Analytical Problem Solving (Wiley, New York, 1979), p. 322.

[19] J. Workman and A. W. Springsteen, Applied Spectroscopy: A Compact Reference for Practitioners (Academic Press, San Diego, 1998), p. 539.

[20] A. Pimpinelli and S. Villain, Physics of Crystal Growth (University Press, Cambridge, 1998), p. 390.

[21] U. Uzar and M. C. Arikan, Bull. Mater. Sci. 34, 287 (2011). 